\title{
Estimation of Model Districts in Andhra Pradesh, India
}

\author{
G. Sunitha ${ }^{1 *}$, N. Vani $^{1}$, B. Aparna ${ }^{1}$ and B. Ramana Murty ${ }^{2}$ \\ ${ }^{1}$ Department of Agricultural Economics, ${ }^{2}$ Department of Statistics and Mathematics, S.V. \\ Agricultural College, Tirupati-517502, Chittoor District, Andhra Pradesh, India \\ *Corresponding author
}

\section{A B S T R A C T}

\section{Keywords}

Sustainability, Model districts, Development

\section{Article Info}

Accepted:

07 August 2020

Available Online:

10 September 2020
The present investigation was done to study the Estimation of Model Districts in Andhra Pradesh. Prem Narain Developmental Index was used to identify the model districts from the composite indices values. The results of the study revealed that in case of Ecological Security, East Godavari ranked first and Kurnool district was given last rank and the composite indices of development ranged from 0 to 0.6331 . In Economic Efficiency the district of Kurnool was stood in last position and the Vishakapatanam ranked last. The composite indices varied from 0 to 0.650 . In case of Social Equity, West Godavari occupied first place and the last position was occupied by Kurnool district where the composite indices ranged from 0 to 0.772 .

\section{Introduction}

Andhra Pradesh economy is mainly based on agriculture and livestock. Sixty per cent of population is engaged in agriculture and other related activities. As of 2011 Census of India, the total population constitutes 70.40 per cent of rural population in the state. Development has been appropriately conceptualized as a process, which improves the quality of life and standard of living of life of the general masses by providing basic necessities of life as well as effecting improvement in their social and economic well -being. Several developmental programmes have been made from five years plans in India in general and in Andhra Pradesh in particular to attain sustainability.
Districts have been taken as unit of analysis. It would be of interest to measure the level of development at district level, since; there has been a growing consensus about the need of district level planning in the state. Estimation of stages of development of districts from composite index values helps in gaining knowledge on the related performance on position of different districts.

\section{Development indicators}

Development is a multi-dimensional process which is continuous in nature and its impact cannot be captured entirely by any single indicator. Moreover, a number of indicators when analysed independently, do not provide 
an integrated and easily understandable picture in reality. Hence, a composite index of development based on various Socioeconomic variables is estimated. In the present study, an attempt has been made to quantify the Socio-economic development of different districts of Andhra Pradesh state where the district level data on Socioeconomic variables for the year 2016-2017 are analysed to estimate the developmental level of districts.

Population density

Proportion of geographical area under forest

Cropping intensity

Livestock density

Net irrigated area

Population growth

Total food grain yield

Total milk production

Net sown area

Fertilizer consumption

Literacy rate

Female literacy rate

Rural road connectivity

Number of commercial bank branches

Number of primary health centres

These above mentioned 15 variables are included under three different indicators viz., Ecological security, Economic Efficiency and Social Equity indicators.

\section{Materials and Methods}

There are several statistical methods which are used for estimating the level of development but most of these methods are having their own limitations. The major limitation arises from the assumptions made about the developmental indicators themselves and their weightage in aggregate index. Keeping in view the limitations of different methods in estimating the level of development, the following statistical procedures are used in this study. Variables for different developmental indicators are taken from different population distributions and these are recorded in different units of measurement. The values of the variables are not quite suitable for combined analysis. Hence, the variables are transformed for the combined analysis as given below.

Let $\left[X_{i j}\right]$ be data matrix giving the values of the variables of $i^{\text {th }}$ district, $i=1,2, \ldots n$ (number of districts)and $j^{\text {th }}$ indicator, $j=1,2$, ... $k$ (number of indicators).

For combined analysis $\left[X_{\mathrm{ij}}\right]$ is transformed to [ $Z_{\mathrm{ij}}$ as follows:

$$
\left[Z_{i \bar{j} j}\right]=\frac{x_{i j}-\overline{x_{j}}}{s_{j}}
$$

Where,

$\overline{X_{j}}=$ mean of the $j^{\text {th }}$ indicator

$S_{j}=$ standard deviation of $\mathrm{j}^{\text {th }}$ indicator

$\left[Z_{i j}\right]$ is the matrix of standardized indicators.

From $\left[Z_{i j}\right]$, identify the best value of each indicator. Let it be denoted as $Z_{o j}$. The best value will be either the maximum value or the minimum value of the indicator depending upon the direction of the impact of indicator on the level of development. For obtaining the pattern of development $C_{i}$ of $i^{\text {th }}$ district, first calculate $P_{i j}$ as follows:

$P_{i j}=\left(Z_{i j}-Z_{o j}\right)^{2}$

For each $i$ and $j$,

Pattern of Development is given by

$C_{i}=\left[\sum_{j=1}^{k} P_{i j j} /(c v)_{j}\right]^{1 / 2}$

$(c v)_{j}=$ coefficient of variation in $X_{i j}$ for $j^{\text {th }}$ indicator

Composite index of development is given by 
$D_{i}=C_{i} / C$

$C=C+3 S D_{i}$

Where,

$C=$ Mean of $C_{i}$

$\mathrm{SD}_{i}=$ Standard Deviation of $C_{i}$

Smaller value of $D_{i}$ will indicate high level of development and higher value of $D_{i}$ will indicate low-level of development. For identifying the model districts for low developed districts, the distance between different pairs of districts based on all the indicators is calculated. The distance between two districts $i$ and $p$ is given by $d_{i p}$ where

$d_{i p}=\left[\sum_{j=1}^{k}\left(Z_{i j}-Z_{p j}\right)^{2}\right]^{1 / 2}$

Where $i=1,2, \ldots . . n$ and $p=1,2, \ldots . n$

Here $d_{i i}=0$ and $d_{i p}=d_{p i}$

Now $d_{i p}$ can be written as,

$d_{i p}=\left[\begin{array}{ccccc}0 & d 12 & . & . & d 1 n \\ d 21 & 0 & \cdot & . & d 2 n \\ \cdot & \cdot & \cdot & \cdot & \cdot \\ \cdot & \cdot & \cdot & \cdot & \cdot \\ d n 1 & d n 2 & . & . & 0\end{array}\right]$

From the above distance matrix, find out the minimum distance for each row. Let the minimum distance for row $i$ is given by $d_{i}$. Obtain the Critical Distance (CD) as follows:

$\mathrm{CD}=d+2 s d$

$s d=$ Standard Deviation of $d_{i}$

Model districts will be identified as follows:

Model districts for district A will be those districts whose composite index of development is less than that of district A and the developmental distance of these districts from district $\mathrm{A}$ is less than or equal to Critical Distance (CD). Thus, model districts will be better developed in comparison to district A. The best value of each developmental indicator of the model districts will be taken up as the potential target of that indicator for district A.

\section{Results and Discussion}

\section{Level of development}

The composite indices of development were assessed for different districts of Andhra Pradesh for Ecological Security, Economic Efficiency and Social equity indicators. Composite index values of different indicators were ranked in an ascending order. District with lowest value of composite index ranked first in the order which indicates high development and district with highest value of composite index stood in last position. Table 1 represents the composite indices of development and ranks of the districts.

From Table 1 in case of Ecological Security, East Godavari ranked first and Kurnool district was given last rank and the composite indices of development ranged from 0 to 0.6331. In Economic Efficiency the district of Kurnool was stood in last position and the Vishakapatanam ranked last. The composite indices varied from 0 to 0.650 . In case of Social Equity, West Godavari occupied first place and the last position was occupied by Kurnool district where the composite indices ranged from 0 to 0.772 .

\section{Stages of development}

Developments of districts were classified under four categories by using fractile classification from the mean and SD values of composite index. The districts were classified 
under high level of development when composite index value is less than or equal to (Mean-SD), high medium level development when composite indices value lies in between (Mean-SD) and Mean, the districts with composite indices in between Mean and
$($ Mean + SD) were in low middle level developed category. Under low level of development districts with composite index values greater than or equal to (Mean $+\mathrm{Sd}$ ) were classified.

Table.1 Composite Index of Development (CI) and Rank of the District

\begin{tabular}{|c|c|c|c|c|c|c|c|}
\hline S.No. & \multirow{2}{*}{ District } & \multicolumn{2}{|c|}{ Ecological Security } & \multicolumn{2}{c|}{ Economic Efficiency } & \multicolumn{2}{c|}{ Social equity } \\
\hline & & C.I & Rank & C.I & Rank & C.I & Rank \\
\hline $\mathbf{1}$ & Srikakulam & 0.3193 & 3 & 0.5815 & 10 & 0.5923 & 11 \\
\hline $\mathbf{2}$ & Vizianagaram & 0.3811 & 4 & 0.5950 & 11 & 0.6264 & 12 \\
\hline $\mathbf{3}$ & Vishakapatanam & 0.5498 & 10 & 0.6501 & 13 & 0.3153 & 7 \\
\hline $\mathbf{4}$ & East Godavari & 0 & 1 & 0.3785 & 6 & 0.1279 & 4 \\
\hline $\mathbf{5}$ & West Godavari & 0.0894 & 2 & 0.4649 & 8 & 0 & 1 \\
\hline $\mathbf{6}$ & Krishna & 0.5242 & 9 & 0.3195 & 4 & 0.0978 & 2 \\
\hline $\mathbf{7}$ & Guntur & 0.4412 & 5 & 0.1384 & 2 & 0.3847 & 9 \\
\hline $\mathbf{8}$ & Prakasham & 0.6208 & 12 & 0.1789 & 3 & 0.3788 & 8 \\
\hline $\mathbf{9}$ & S.P.S.Nellore & 0.4958 & 6 & 0.5709 & 9 & 0.1873 & 5 \\
\hline $\mathbf{1 0}$ & Y.S.R.Kadapa & 0.5135 & 8 & 0.4483 & 7 & 0.2230 & 6 \\
\hline $\mathbf{1 1}$ & Kurnool & 0.6331 & 13 & 0 & 1 & 0.7729 & 13 \\
\hline $\mathbf{1 2}$ & Anantapur & 0.5923 & 11 & 0.3614 & 5 & 0.4408 & 10 \\
\hline $\mathbf{1 3}$ & Chittoor & 0.5061 & 7 & 0.6256 & 12 & 0.1143 & 3 \\
\hline
\end{tabular}

Table.2 Number of Districts and percentage area and population under different stage of development

\begin{tabular}{|c|c|c|c|c|}
\hline Indicators & $\begin{array}{c}\text { Stage of } \\
\text { Development }\end{array}$ & No. of districts & Area (\%ge) & $\begin{array}{c}\text { Population } \\
\text { (\%ge) }\end{array}$ \\
\hline Ecological & High & 2 & 13.06 & 18.65 \\
Security & High middle & 2 & 7.53 & 10.17 \\
& Low middle & 8 & 68.41 & 62.88 \\
& Low & 1 & 10.85 & 8.17 \\
\hline Economic & High & 3 & 28.63 & 24.87 \\
Efficiency & High middle & 3 & 24.86 & 27.94 \\
& Low middle & 5 & 30.17 & 30 \\
& Low & 2 & 16.19 & 17.06 \\
\hline Social Equity & High & 2 & 10.51 & 17.16 \\
& High middle & 5 & 41.47 & 39.44 \\
& Low middle & 3 & 29.49 & 24.93 \\
& Low & 3 & 18.38 & 18.34 \\
\hline
\end{tabular}


Table.3 Model Districts for low developed districts

\begin{tabular}{|c|c|}
\hline Low developed districts & Model districts \\
\hline Kurnool & $\begin{array}{c}\text { Krishna, Prakasham, S.P.S.Nellore, Kadapa, } \\
\text { Anantapur, Chittoor }\end{array}$ \\
\hline Vishakapatanam & $\begin{array}{c}\text { Srikakulam, Vizianagaram, S.P.S.Nellore, } \\
\text { Chittoor }\end{array}$ \\
\hline
\end{tabular}

In Ecological Security development, out of 13 districts, two districts viz., East Godavari and West were found to be in high level of development category which covers an area of about 13.06 per cent and a population of 18.65 per cent in the state (Table 2). Two districts, Srikakulam and Vizianagaram with an overall area and population coverage of 7.52 per cent and 10.17 per cent in the state respectively categorized under high middle developed category. Eight low middle developed districts were Vishakapatanam, Krishna, Guntur, Prakasham, S.P.S. Nellore, Y.S.R. Kadapa, Anantapur and Chittoor which occupies an area of about 68.41 per cent and a population of 62.88 per cent. Krishna district falls under low developed district which contributes 10.85 per cent of area and 8.17 per cent of population of the state.

In case of Economic Efficiency, Guntur, Prakasham and Kurnool districts were classified under high level of development. In high middle level of development three districts like East Godavari, Anantapur and Krishna districts were kept. Srikakulam, Vizianagaram, West Godavari, S.P.S. Nellore, Y.S.R.Kadapa placed under low middle level of development. Vishakapatanam and Chittoor districts stood in low developed level.

In Social Equity, high developed category occupied by two districts namely West Godavari and Krishna. Five districts under high middle level of development were Vishakapatanam, East Godavari, S.P.S.
Nellore, Y.S.R. Kadapa and Chittoor. Districts like Guntur, Prakasham and Anantapur classified into low middle level of development. Low developed districts were Srikakulam, Vizianagaram and Kurnool.

\section{Identification of model districts for low development districts}

Model districts are those districts whose composite index values are more than that of a low developed district and developmental distance from particular low developed district is less than or equal to Critical Distance (CD). They can serve as yardsticks to improve the conditions of poorly developed districts by fixing certain benchmark values of developmental levels to the low developed districts. Hence model districts can be called better developed districts compared to the low developed districts.

Model districts are better developed than low developed districts. From the fractile classification low developed districts were classified which includes the districts either from Ecological Security, Economic Efficiency or social Equity indicators. Model districts identification is essential to fix potential targets to the low developed districts for the indicators like Ecological Security, Economic Efficiency and Social Equity.

Districts categorized under low level of development were Kurnool and Vishakapatanam because of the reason that Kurnool district performed low in Ecological Security and Social Equity where the model 
districts identified for Kurnool district were Krishna, Prakasham, S.P.S. Nellore, Y.S.R. Kadapa, Anantapur and Chittoor. Vishakapatanam performed low in Ecological Security and Economic Efficiency and the model districts were Srikakulam, Vizianagaram, S.P.S. Nellore and Chittoor (Table 3).

In conclusion the findings of the present study revealed that in Ecological Security development, out of 13 districts, two districts viz., East Godavari and West were found to be in high level of development category. Krishna district falls under low level of development. In Social Equity, high developed category occupied by two districts namely, West Godavari and Krishna. Vishakapatanam and Chittoor districts stood in low level of development. In Social Equity, high developed category occupied by two districts namely West Godavari and Krishna. Low developed districts were Srikakulam, Vizianagaram and Kurnool. Results also reveal that the model districts identified are better developed than low developed districts viz., Kurnool and Vishakapatanam.

\section{References}

Bhatia, B. K and Rai, S. C. 2004. Evaluation of socio-economic development in small areas. Project Report, Planning Commission, Government of India, New Delhi.

Narain, P., Bhatia, V. K and Rai, S. C. 2012. Pattern of regional disparities in socioeconomic in West Bengal. Journal of Indian Society of Agricultural Statistics, 65(1), 27-35.

Narain, P., Rai, S.C and Shanti Sarup (1991). Statistical evaluation of development on socio-economic front. Journal of Indian Society of Agricultural Statistics., 43, 329-345.

Narain, P., Rai, S.C and Shanti Sarup 1992. Evaluation of economic development in India. Souvenir of I I th economic Development Conference in "Complementarity of Agriculture and Industry in Development". Instt. Trade \& Industrial Development, New Delhi, 67-77.

Narain, P, Rai, S.C., Sharma, S.D and Bhatia, V.K. 2007. Statistical evaluation of social development at district level. Journal of Indian Society of Agricultural Statistics. 61, 216-226.

Rai, S.C and Bhatia, V.K. 2004. Dimension of regional disparities in socio- economic development of Assam. Journal of Indian Society of Agricultural Statistics. 57, 178-190.

\section{How to cite this article:}

Sunitha, G., N. Vani, B. Aparna and Ramana Murty, B. 2020. Estimation of Model Districts in Andhra Pradesh, India. Int.J.Curr.Microbiol.App.Sci. 9(09): 405-410. doi: https://doi.org/10.20546/ijcmas.2020.909.051 